\title{
Emilie Savage-Smith, éd., Magic and Divination in
}

\section{Early Islam}

Aldershot, Ashgate, coll. « The Formation of the Classical Islamic

World », 42, 2004, 394 p.

\section{Constant Hamès}

\section{CpenEdition}

Journals

Édition électronique

URL : http://journals.openedition.org/assr/4041

DOI : 10.4000/assr.4041

ISSN : $1777-5825$

Éditeur

Éditions de l'EHESS

Édition imprimée

Date de publication : 1 décembre 2006

Pagination : 115-283

ISBN : 2-7132-2124-2

ISSN : 0335-5985

Référence électronique

Constant Hamès, « Emilie Savage-Smith, éd., Magic and Divination in Early Islam », Archives de sciences sociales des religions [En ligne], 136 | octobre - décembre 2006, document 136-96, mis en ligne le 14 février 2007, consulté le 21 septembre 2020. URL : http://journals.openedition.org/assr/4041 ; DOI : https://doi.org/10.4000/assr.4041

Ce document a été généré automatiquement le 21 septembre 2020

(c) Archives de sciences sociales des religions 


\title{
Emilie Savage-Smith, éd., Magic and Divination in Early Islam
}

\author{
Aldershot, Ashgate, coll. « The Formation of the Classical Islamic \\ World », 42, 2004, 394 p.
}

\section{Constant Hamès}

1 Il ne s'agit pas d'un ouvrage d'auteur, même collectif, mais, selon la formule de la collection, d'un recueil, d'une "sélection critique des publications scientifiques (...) pour comprendre la période de formation de l'histoire islamique, approximativement entre 600 et $950 \mathrm{AD}$ ».

2 En tant qu'experte dans le domaine de la magie et de la divination dans l'histoire musulmane, l'auteure a procédé à une présentation générale du sujet, assortie d'une bibliographie de base. Elle a ensuite fait un choix et réédité des articles jugés importants, datant de ces dernières décades, voire bien antérieurs. On ne trouvera pas, dans la présentation, de réflexion particulière sur la notion de «magic » et on restera étonné de l'annonce faite d'emblée et sans suite "qu'il y a à peu près autant de définitions de la magie et de la divination que d'auteurs écrivant sur le sujet »...

3 Les thèmes abordés par les textes réédités forment en effet un canevas très large consacré à des croyances et à des pratiques dont on aimerait connaître la parenté ou les structures communes: les jinn (J. Henninger); les croyances hermétiques transmises par les Sabéens de Harrân (F.R. Peters); la théorie de la guérison par la magie (M.W. Dols) ; le bâton de Moïse dans la magie arabe (A. Fodor) ; le déchiffrement des talismans arabes (T. Canaan, 1938), certainement le travail le plus important sur le sujet jusqu'à nos jours; les sceaux islamiques (V. Porter); les prévisions météorologiques dans le monde arabe (Ch. Burnett); la géomancie islamique (E. Savage-Smith et M. Smith); trois fatwa d'Ibn Taymiyya sur l'astrologie (Y.J. Michot) ; le rôle de l'astrologue dans la société musulmane médiévale (G. Saliba). Les articles comprennent chacun leur bibliographie et l'ouvrage comporte un index général, hormis les noms d'auteurs.

4 La précision du titre « in early Islam » est à prendre dans un sens historique très large puisqu'il y est question par exemple, d'ouvrages ou de pièces du xiII ${ }^{e}$ siècle, ou du $\mathrm{xx}^{\mathrm{e}}$, 
puisque le travail de T. Canaan porte sur des objets et des données de terrain de la Palestine des années 1920-30.

5 L'intérêt de ces textes, à côté d'un apport bibliographique fondamental, se situe dans le «balayage» d'un ensemble de pratiques et de techniques, dans l'aperçu de leur héritage souvent préislamique et donc de leur islamisation historique. À l'inverse, la juxtaposition purement empirique de travaux divers - même s'il s'agit sans doute d'insister sur la diversité - laisse quelque peu sur sa faim et un effort de théorisation, au moins dans le classement des différents domaines, du point de vue islamique ou scientifique, aurait apporté plus de cohérence à l'ensemble. On regrettera aussi que la bibliographie, sauf exception, fasse l'impasse sur toute une production française. 